\title{
Management of heart failure with preserved ejection fraction
}

\section{Emma Gard \\ Final year MBBS student \\ Shane Nanayakkara \\ Interventional cardiology fellow ${ }^{2}$ \\ David Kaye \\ Professor? \\ Director, Cardiology² \\ $\mathrm{Head}^{3}$ \\ Principal research fellow ${ }^{4}$ \\ Harry Gibbs \\ Deputy director, General \\ Medicine $^{2}$ \\ Program director, \\ Outpatients Program² \\ 'Monash University, \\ Clayton, Vic. \\ 2 Department of Cardiology, \\ Alfred Health, Melbourne \\ ${ }^{3}$ Heart Failure Research \\ Group, Baker Heart \\ and Diabetes Institute, \\ Melbourne \\ ${ }^{4}$ National Health and \\ Medical Research Council, \\ Canberra}

\section{Keywords}

diet, diuresis, exercise, heart failure

Aust Prescr 2020;43:12-7

https://doi.org/10.18773/

austprescr.2020.006

\section{SUMMARY}

Heart failure with preserved ejection fraction is a highly heterogenous disease. There is emerging evidence that treatment should be tailored to the individual's associated comorbidities.

No current algorithms exist for the management of heart failure with preserved ejection fraction. Conventional therapies used in heart failure with reduced ejection fraction are yet to show a mortality benefit.

Key treatment objectives include control of hypertension and fluid balance.

Common comorbidities include coronary artery disease, atrial fibrillation, obesity, diabetes, renal impairment and pulmonary hypertension. These comorbidities should be considered in all patients and treatment optimised.

\section{Introduction}

Heart failure usually presents as exercise intolerance due to exertional dyspnoea. It is categorised according to left ventricular ejection fraction:

- heart failure with preserved ejection fraction (HFpEF, also known as diastolic dysfunction)

- heart failure with reduced ejection fraction (HFrEF).

Heart failure affects over half a million Australians and accounts for $1.6 \%$ of all hospitalisations.

Approximately half of these cases are due to HFpEF. Despite sharing the same clinical symptoms, patients with a preserved ejection fraction tend to be older, more frequently female and obese, and have higher rates of comorbidities compared to those with a reduced ejection fraction. ${ }^{1-3}$

Although there have been significant advances in the management of HFrEF with several pharmacologic and device-based therapies recommended by guidelines, the current therapeutic options in HFpEF may alleviate symptoms but do not significantly reduce mortality.

\section{Pathophysiology}

Despite the marked differences in systolic function, patients with preserved ejection fraction and reduced ejection fraction can share the same level of functional impairment. Echocardiography is therefore vital to differentiate between them. Myocardial stiffening, reduced left ventricular compliance and impaired relaxation in diastole are characteristic, ${ }^{4}$ although peripheral mechanisms have also been implicated, such as impaired oxygen uptake and remodelling of skeletal muscle. Myocardial stiffening results in elevated left ventricular pressures during filling, with further transmission to the left atrium and consequent pulmonary hypertension. This in part leads to the sensation of breathlessness. Left atrial myopathy is associated with worse haemodynamic features, likely due to a greater transmission of pressure. ${ }^{5}$

When considering HFpEF, it is important to exclude infiltrative cardiomyopathies. Approximately 13\% of patients with HFpEF have cardiac amyloidosis. Patients with significantly increased wall thickness, low Doppler velocities, early-onset bilateral carpal tunnel syndrome, and other systemic manifestations of amyloidosis should undergo more detailed evaluation. Both cardiac MRI and nuclear imaging studies provide non-invasive methods of diagnosis.

\section{Diagnosis}

The diagnosis of HFpEF is challenging, in part due to clinical heterogeneity and the primary manifestation of symptoms and abnormalities, often with exertion. The condition is defined by a left ventricular ejection fraction of at least $50 \%$, in combination with elevated biomarkers (either BNP or NT-proBNP) and echocardiographic features of structural or functional impairment. ${ }^{1,6}$ Up to $15 \%$ of patients can have normal natriuretic peptide measures at rest, and the sensitivity of resting echocardiography is limited. Although multiple echocardiography criteria exist, including an elevated E/e' and left ventricular mass index, the presence of an enlarged left atrium, with a preserved ejection fraction and normal mitral valvular function, should prompt consideration of HFpEF.

The $\mathrm{H}_{2}$ FPEF score, which combines clinical and echocardiographic characteristics, is a useful and clinically validated screening tool for patients 
presenting with dyspnoea (Table). ${ }^{7}$ It can help guide clinicians to refer patients on for exercise-based evaluation, either with invasive haemodynamics or diastolic stress testing with echocardiography.

Given the diverse spectrum of comorbidities associated with HFpEF, it is suggested that management be tailored to these comorbidities. ${ }^{8-10}$ Distinct comorbidity phenotypes have been identified with differing long-term outcomes across groups. ${ }^{8}$ Hypertension, fluid retention, obesity and metabolic syndrome, pulmonary hypertension, cardiac fibrosis and ischaemia, and renal impairment have been identified as treatment targets (and the key determinants of phenotype) in patients with HFpEF.11

\section{Management}

General principles for the management of HFpEF are outlined in the Box.12 Structured weight-loss programs and exercise-based rehabilitation are recommended, as well as adequate control of comorbidities such as hypertension, and particularly atrial fibrillation and diabetes.

\section{Non-drug interventions}

Salt and fluid restriction are advised in HFpEF, although evidence for benefit is lacking. ${ }^{4,13}$ Cessation of smoking, limiting alcohol intake and a high-fibre diet are advised..$^{14}$ Exercise training appears to improve exercise capacity and quality of life. ${ }^{15}$ There is a dose-dependent decrease in the risk of HFpEF with a lower BMI and increasing exercise. However, the amount of exercise needed to be beneficial may be greater than standard recommendations. Further studies are in progress. ${ }^{16}$

\section{Pharmacotherapy}

In contrast to HFrEF, ACE inhibitors, angiotensin receptor antagonists (sartans), aldosterone antagonists, beta blockers and digoxin have not shown a mortality benefit in HFpEF. ${ }^{17-22}$ However, study populations in the trials were variable because of varying definitions of the disease and difficulty in confidently diagnosing HFpEF. This clouded interpretation of the results. ${ }^{23}$ In the absence of conclusive data, pharmacotherapy for HFpEF varies widely.

\section{Neurohormonal antagonists}

Hypertension is a major risk factor for HFpEF. Blood pressure management is paramount, and an ACE inhibitor or angiotensin receptor antagonist is appropriate. ${ }^{6}$ Despite not having a significant mortality benefit, perindopril, candesartan and spironolactone may have value in reducing the risk of hospitalisations from heart failure through inhibition of the renin-angiotensin-aldosterone system. ${ }^{17-19}$

\section{Table Screening tool for heart failure with preserved} ejection fraction in patients with dyspnoea

\begin{tabular}{|c|c|c|c|}
\hline & Clinical variable & Values & Points \\
\hline \multirow[t]{2}{*}{$\mathrm{H}_{2}$} & Heavy & Body mass index $>30 \mathrm{~kg} / \mathrm{m}^{2}$ & 2 \\
\hline & Hypertensive & $\geq 2$ antihypertensive drugs & 1 \\
\hline $\mathbf{F}$ & Atrial fibrillation & Paroxysmal or persistent & 3 \\
\hline $\mathbf{P}$ & $\begin{array}{l}\text { Pulmonary } \\
\text { hypertension }\end{array}$ & $\begin{array}{l}\text { Echocardiographic estimated pulmonary } \\
\text { artery systolic pressure }>35 \mathrm{mmHg}\end{array}$ & 1 \\
\hline E & Elderly & Age $>60$ & 1 \\
\hline $\mathbf{F}$ & Filling pressure & Echo derived E/e' >9 & 1 \\
\hline
\end{tabular}

$\mathrm{H}_{2}$ FPEF score and point allocation: a diagnosis of HFpEF is likely with a total score $\geq 6$, intermediate with a score of 2-5, and unlikely with a score of $\leq 1$.

Source: Adapted from reference 7

\section{Box Principles of management in patients with heart failure with preserved ejection fraction}

$\begin{array}{ll}\begin{array}{ll}\text { Avoid tachycardia } \\ \text { Blood pressure }\end{array} & \begin{array}{l}\text { For patients with atrial fibrillation, use digoxin or beta blockers } \\ \text { control }\end{array} \\ \begin{array}{ll}\text { ACE inhibitors, angiotensin receptor antagonists (sartans) } \\ \text { or mineralocorticoid receptor antagonists may be of the } \\ \text { greatest benefit }\end{array} \\ \begin{array}{ll}\text { Optimise cardiac and noncardiac conditions, particularly atrial } \\ \text { fibrillation, obesity and diabetes mellitus }\end{array} \\ \text { Diuretics } & \begin{array}{l}\text { Use loop diuretics to relieve congestion, with close monitoring } \\ \text { of renal function }\end{array} \\ \text { Exercise training } & \text { Improves exercise capacity and quality of life }\end{array}$

Source: Adapted from reference 12

The TOPCAT trial assessed 3445 patients with HFpEF (with an ejection fraction over 45\%). Despite an overall negative outcome, later investigation found significant geographical heterogeneity in outcomes. Patients from Russia and Georgia appeared not to have the structural and functional features of a preserved ejection fraction. When they were removed from the analysis, spironolactone reduced hospitalisations. The PEP-CHF trial assessed the role of perindopril, with a weak signal of reduction in hospitalisation. ${ }^{17}$

Care must be taken to monitor for renal dysfunction and hyperkalaemia when starting spironolactone, particularly as renal dysfunction is prevalent in people with HFpEF. A combination of multiple antihypertensives may be needed to adequately control blood pressure, with ambulatory blood pressure monitoring providing the most accurate measure of control. 


\section{Diuretics}

Diuresis helps lower left ventricular pressures, reducing pulmonary congestion and improving symptoms. ${ }^{24}$ Furosemide (frusemide), a loop diuretic, is most commonly used. Patients with preserved ejection fraction are often more sensitive to diuresis than those with reduced ejection fraction and are at greater risk of developing renal dysfunction and hypotension.

\section{Statins}

Aside from their cholesterol-lowering benefits, statins also target systemic inflammation. ${ }^{25}$ This is an important contributor to the pathogenesis of HFpEF. Their use has been associated with lower mortality in these patients, ${ }^{26}$ even in those without coronary artery disease. ${ }^{27}$ However, further trials are needed to confirm these results and elucidate the mechanism of action.

\section{Sacubitril with valsartan}

Sacubitril with valsartan inhibits both neprilysin and the angiotensin AT receptor. In addition, neprilysin inhibition increases natriuretic and vasoactive peptides, leading to natriuresis, diuresis and vasodilation. ${ }^{28}$ Although a significant reduction in mortality was seen with the combination in HFrEF, the recent PARAGON-HF trial ${ }^{29}$ found it did not significantly reduce hospitalisations and mortality in patients with HFpEF. ${ }^{30,31}$

\section{Managing comorbidities}

Patients with HFpEF frequently display cardiac and non-cardiac comorbidities including coronary artery disease, hypertension, obesity and diabetes. ${ }^{1-3}$ Some experts believe these extra-cardiac comorbidities lead to systemic inflammation, a key driver in the development of HFpEF. ${ }^{32}$ These comorbidities must be considered as part of the initial evaluation, and aggressively managed.

\section{Obesity}

Obesity is associated with diastolic dysfunction and worse left ventricular remodelling. ${ }^{33,34}$ Patients with obesity have increased epicardial fat, limited cardiac reserve, worse pulmonary vascular disease and greater biventricular remodelling..$^{35}$ Observational studies support the benefit of weight loss and exercise in improving quality of life and survival. ${ }^{36}$ Caloric restriction is well tolerated and significantly improves heart failure symptoms and exercise capacity. ${ }^{37}$

\section{Type 2 diabetes}

Tight glycaemic control is important and metformin is the first-line oral hypoglycaemic drug. ${ }^{6}$ Sodium-glucose co-transporter 2 inhibitors have shown significant benefits in HFrEF, reducing mortality in patients with and without diabetes..$^{38,39}$ These drugs may be beneficial in HFpEF by inducing osmotic diuresis, natriuresis and weight loss, and reducing heart failure hospitalisations and all-cause mortality. ${ }^{40}$ Several trials are currently assessing outcomes in HFpEF. ${ }^{41}$

\section{Renal impairment}

HFpEF commonly co-exists with renal dysfunction, in part due to shared comorbid risk factors such as aging, hypertension and diabetes, and to the adverse haemodynamics promoting cardiorenal syndrome. ${ }^{42}$ In patients with a comorbid chronic kidney disease phenotype, cardiorenal syndrome appears to result from renal venous congestion due to pulmonary hypertension and right ventricular dysfunction. ${ }^{8}$ In these cases, careful diuresis may be required, and haemodynamic monitoring may be helpful to titrate therapy. ${ }^{43}$

\section{Atrial fibrillation and rate control}

Atrial fibrillation co-exists in approximately one-third of patients with $\mathrm{HFpEF},{ }^{44}$ and may precede or follow the development of heart failure. ${ }^{45}$ Patients with atrial fibrillation display elevated filling pressures and reduced cardiac output. The loss of atrial contraction in late diastole compounds the impaired left ventricular filling. As a result, the atrial myopathy promotes atrial fibrosis and higher transmission of left ventricular pressures onto the pulmonary circulation. ${ }^{46}$ In suitable candidates, rhythm control should be considered in view of the potential benefits, although trial data are lacking. If this fails, traditional management principles apply, with long-term rate control and anticoagulation. Catheter ablation appears safe, with similar functional improvements and rates of recurrence as in patients with HFrEF. ${ }^{47}$ Further studies are in progress. ${ }^{48}$

Rate control has also been suggested as a treatment target for patients in sinus rhythm to maximise diastolic filling. An increased heart rate is associated with cardiovascular death and hospitalisation in HFpEF, ${ }^{49}$ although pharmacological rate control has yet to show a mortality benefit. ${ }^{50,51}$ It may even be detrimental to the patient's exercise capacity ${ }^{52}$ as it exacerbates their inability to compensate for exercise demands by inducing chronotropic incompetence. ${ }^{53}$ For this reason, adaptive atrial pacing has been suggested as an alternative to pharmacological rate control. ${ }^{54}$

\section{Coronary artery disease}

Coronary artery disease affects over half of patients with HFpEF and is associated with increased mortality. ${ }^{55}$ The symptom of exertional dyspnoea may indicate angina, and current recommendations advise exclusion of coronary disease. The decision for revascularisation is independent of the HFpEF diagnosis, and should be considered where appropriate. ${ }^{55}$ 


\section{Right ventricular dysfunction}

Chronic pulmonary hypertension, driven by persistent elevations in left-sided pressures, can lead to right ventricular failure in HFpEF.56,57 These changes are typically seen later in the course of the disease and indicate a worse prognosis. Preliminary results with milrinone are promising, but further trials of these therapies are required. ${ }^{58}$

\section{Drugs to avoid}

Avoiding or minimising the use of non-steroidal anti-inflammatory drugs is recommended in heart failure, due to their association with sodium and fluid retention and increased risk of renal impairment and hospitalisations due to heart failure..$^{59}$

Glitazones are not recommended due to the risk of worsening heart failure related to salt and water retention. ${ }^{60}$ Despite being associated with worse outcomes in HFrEF, non-dihydropyridine calcium channel blockers appear safe to use in patients with preserved ejection fraction, although they are not necessarily beneficial. ${ }^{61}$

The combination of ACE inhibitors and neprilysin inhibitors can lead to angioedema, and they should not be used within 36 hours of each other. ${ }^{6,62} \mathrm{~A}$ randomised controlled trial of isosorbide mononitrate demonstrated a worsening of exercise capacity, and is not recommended for HFpEF. Sildenafil has also been rigorously tested in several randomised trials and has not shown harm or benefit. ${ }^{63}$

\section{Devices}

The lack of benefit from drug therapies is likely due to the myriad of pathways activated in HFpEF, with the only definite uniting pathology being elevated left ventricular filling pressures. Consequently, devices targeting this pathway have been tested in trials over the past few years.

\section{Interatrial septal device}

A transcatheter interatrial left to right shunt has been shown to offset the high left atrium pressure that develops in HFpEF. ${ }^{64-66}$ One-year observational outcomes have shown the safety of this device, with increased exercise tolerance, quality of life, and a trend toward decreased hospitalisations and heart failure symptoms. ${ }^{67,68} \mathrm{~A}$ trial is under way. ${ }^{69}$

\section{Implantable pulmonary arterial pressure monitoring}

Continuous monitoring of haemodynamics through an implanted device allows for assessment of diastolic left ventricular pressures, and early appropriate administration of diuretics. The CHAMPION trial demonstrated reduced hospitalisations with this device by alerting physicians to high pulmonary pressures and directing subsequent changes to medicines. ${ }^{70,71}$ This device is available for clinical use, however it is currently limited by availability and cost.

\section{Future directions}

In HFrEF, there is substantial evidence of improved outcomes with multidisciplinary care (including GPs, cardiologists, specialist nurses and allied health). ${ }^{13}$ This approach should also be considered in patients with HFpEF. Clinics specialising only in HFpEF have shown benefits overseas, particularly in identifying 'treatable' forms of the condition such as amyloidosis, and in referring patients on to relevant clinical trials. ${ }^{72}$

\section{Conclusion}

$\mathrm{HFpEF}$ is a diagnostic and therapeutic challenge. Early identification of the disease along with aggressive control of comorbidities are key to management. Determining a patient's associated comorbidities will allow targeted use of available therapies. $<$

Harry Gibbs has received fees for presentations and advisory board attendance from Bayer and Bristol-Myers Squibb.

\section{REFERENCES}

1. Dunlay SM, Roger VL, Redfield MM. Epidemiology of heart failure with preserved ejection fraction. Nat Rev Cardiol 2017;14:591-602. https://doi.org/10.1038/nrcardio.2017.65

2. Chamberlain AM, St Sauver JL, Gerber Y, Manemann SM, Boyd CM, Dunlay SM, et al. Multimorbidity in heart failure: a community perspective. Am J Med 2015;128:38-45 https://doi.org/10.1016/j.amjmed.2014.08.024

3. Ather S, Chan W, Bozkurt B, Aguilar D, Ramasubbu K, Zachariah AA, et al. Impact of noncardiac comorbidities on morbidity and mortality in a predominantly male population with heart failure and preserved versus reduced ejection fraction. J Am Coll Cardiol 2012;59:998-1005. https://doi.org/ 10.1016/j.jacc.2011.11.040

4. Reddy YN, Borlaug BA. Heart failure with preserved ejection fraction. Curr Probl Cardiol 2016;41:145-88. https://doi.org/ 10.1016/j.cpcardiol.2015.12.002

5. Telles F, Nanayakkara S, Evans S, Patel HC, Mariani JA, Vizi D, et al. Impaired left atrial strain predicts abnormal exercise haemodynamics in heart failure with preserved ejection fraction. Eur J Heart Fail 2019;21:495-505. https://doi.org/ 10.1002/ejhf.1399
6. Atherton JJ, Sindone A, De Pasquale CG, Driscoll A, MacDonald PS, Hopper I, et al.; NHFA CSANZ Heart Failure Guidelines Working Group. National Heart Foundation of Australia and Cardiac Society of Australia and New Zealand: Guidelines for the prevention, detection, and management of heart failure in Australia 2018. Heart Lung Circ 2018;27:1123-208. https://doi.org/10.1016/j.hlc.2018.06.1042

7. Reddy YN, Carter RE, Obokata M, Redfield MM, Borlaug BA A simple, evidence-based approach to help guide diagnosis of heart failure with preserved ejection fraction. Circulation 2018;138:861-70. https://doi.org/10.1161/ CIRCULATIONAHA.118.034646

8. Shah SJ, Katz DH, Selvaraj S, Burke MA, Yancy CW, Gheorghiade $\mathrm{M}$, et al. Phenomapping for novel classification of heart failure with preserved ejection fraction. Circulation 2015;131:269-79. https://doi.org/10.1161/ CIRCULATIONAHA.114.010637

9. Ferrari R, Böhm M, Cleland JG, Paulus WJ, Pieske B, Rapezzi C, et al. Heart failure with preserved ejection fraction: uncertainties and dilemmas. Eur J Heart Fail 2015;17:665-71. https://doi.org/10.1002/ejhf.304 
10. Xanthopoulos A, Triposkiadis F, Starling RC. Heart failure with preserved ejection fraction: Classification based upon phenotype is essential for diagnosis and treatment. Trends Cardiovasc Med 2018;28:392-400. https://doi.org/ 10.1016/j.tcm.2018.01.001

11. Senni M, Paulus WJ, Gavazzi A, Fraser AG, Díez J, Solomon SD, et al. New strategies for heart failure with preserved ejection fraction: the importance of targeted therapies for heart failure phenotypes. Eur Heart J 2014;35:2797-815. https://doi.org/10.1093/eurheartj/ehu204

12. Nanayakkara S, Mariani J, Kaye D. Heart failure with preserved ejection fraction: improving diagnosis and management. Med Today 2017;18:37-42. https://medicinetoday.com.au/ 2017/january/feature-article/heart-failure-preserved-ejectionfraction-diagnosis-and-management

13. Rossignol P, Hernandez AF, Solomon SD, Zannad F. Heart failure drug treatment. Lancet 2019;393:1034-44. https://doi.org/10.1016/S0140-6736(18)31808-7

14. Wang Y, Tuomilehto J, Jousilahti P, Antikainen R, Mähönen M, Katzmarzyk PT, et al. Lifestyle factors in relation to heart failure among Finnish men and women. Circ Heart Fail 2011;4:607-12. https://doi.org/10.1161/CIRCHEARTFAILURE.111.962589

15. Pandey A, Parashar A, Kumbhani D, Agarwal S, Garg J, Kitzman D, et al. Exercise training in patients with heart failure and preserved ejection fraction: meta-analysis of randomized control trials. Circ Heart Fail 2015;8:33-40. https://doi.org/10.1161/CIRCHEARTFAILURE.114.001615

16. Pandey A, LaMonte M, Klein L, Ayers C, Psaty BM, Eaton CB, et al. Relationship between physical activity, body mass index, and risk of heart failure. J Am Coll Cardio 2017;69:1129-42. https://doi.org/10.1016/j.jacc.2016.11.081

17. Cleland JG, Tendera M, Adamus J, Freemantle N, Polonski L, Taylor J; PEP-CHF Investigators. The perindopril in elderly people with chronic heart failure (PEP-CHF) study. Eur Heart J 2006;27:2338-45. https://doi.org/10.1093/eurheartj/ehl250

18. Yusuf S, Pfeffer MA, Swedberg K, Granger CB, Held P McMurray JJ, et al.; CHARM Investigators and Committees. Effects of candesartan in patients with chronic heart failure and preserved left-ventricular ejection fraction: the CHARM-Preserved Trial. Lancet 2003:362:777-81. https://doi.org/10.1016/S0140-6736(03)14285-7

19. Pitt B, Pfeffer MA, Assmann SF, Boineau R, Anand IS, Claggett B, et al.; TOPCAT Investigators. Spironolactone for heart failure with preserved ejection fraction. N Engl J Med 2014;370:1383-92. https://doi.org/10.1056/NEJMoa1313731

20. Massie BM, Carson PE, McMurray JJ, Komajda M, McKelvie R, Zile MR, et al.; I-PRESERVE Investigators. Irbesartan in patients with heart failure and preserved ejection fraction. N Engl J Med 2008;359:2456-67. https://doi.org/10.1056/NEJMoa0805450

21. Yamamoto K, Origasa H, Hori M; J-DHF Investigators. Effects of carvedilol on heart failure with preserved ejection fraction: the Japanese Diastolic Heart Failure Study (J-DHF). Eur J Heart Fail 2013;15:110-8. https://doi.org/10.1093/eurjhf/hfs141

22. Ahmed A, Rich MW, Fleg JL, Zile MR, Young JB Kitzman DW, et al. Effects of digoxin on morbidity and mortality in diastolic heart failure: the ancillary digitalis investigation group trial. Circulation 2006;114:397-403. https://doi.org/10.1161/CIRCULATIONAHA.106.628347

23. Kelly JP, Mentz RJ, Mebazaa A, Voors AA, Butler J, Roessig $\mathrm{L}$, et al. Patient selection in heart failure with preserved ejection fraction clinical trials. J Am Coll Cardiol 2015;65:1668-82. https://doi.org/10.1016/j.jacc.2015.03.043

24. Borlaug BA. The pathophysiology of heart failure with preserved ejection fraction. Nat Rev Cardiol 2014;11:507-15. https://doi.org/10.1038/nrcardio.2014.83

25. Quist-Paulsen P. Statins and inflammation: an update. Curr Opin Cardiol 2010;25:399-405. https://doi.org/10.1097/ HCO.0b013e3283398e53

26. Fukuta $\mathrm{H}$, Goto $\mathrm{T}$, Wakami K, Ohte N. The effect of statins on mortality in heart failure with preserved ejection fraction: a meta-analysis of propensity score analyses. Int J Cardiol 2016:214:301-6. https://doi.org/10.1016/j.ijcard.2016.03.186

27. Marume K, Takashio S, Nagai T, Tsujita K, Saito Y, Yoshikawa T, et al. Effect of statins on mortality in heart failure with preserved ejection fraction without coronary artery disease- report from the JASPER study. Circ J 2019;83:357-67. https://doi.org/10.1253/circj.CJ-18-0639

28. Gori M, D’Elia E, Senni M. Sacubitril/valsartan therapeutic strategy in HFpEF: Clinical insights and perspectives. Int J Cardiol 2019;281:158-65. https://doi.org/10.1016/ j.ijcard.2018.06.060
29. Solomon SD, McMurray JJV, Anand IS, et al. Angiotensinneprilysin inhibition in heart failure with preserved ejection fraction. N Engl J Med 2019;381:1609-20. https://doi.org/ 10.1056/NEJMoa1908655

30. Solomon SD, Rizkala AR, Gong J, Wang W, Anand IS, Ge J, et al. Angiotensin receptor neprilysin inhibition in heart failure with preserved ejection fraction: rationale and design of the PARAGON-HF trial. JACC Heart Fail 2017;5:471-82. https://doi.org/10.1016/j.jchf.2017.04.013

31. Solomon SD, Rizkala AR, Lefkowitz MP, Shi VC, Gong J, Anavekar N, et al. Baseline characteristics of patients with heart failure and preserved ejection fraction in the PARAGON-HF trial. Circ Heart Fail 2018;11:e004962. https://doi.org/10.1161/CIRCHEARTFAILURE.118.004962

32. Paulus WJ, Tschöpe C. A novel paradigm for heart failure with preserved ejection fraction: comorbidities drive myocardial dysfunction and remodeling through coronary microvascular endothelial inflammation. J Am Coll Cardiol 2013;62:263-71. https://doi.org/10.1016/j.jacc.2013.02.092

33. Russo C, Jin Z, Homma S, Rundek T, Elkind MS, Sacco RL, et al. Effect of obesity and overweight on left ventricular diastolic function: a community-based study in an elderly cohort. J Am Coll Cardiol 2011;57:1368-74. https://doi.org/ 10.1016/j.jacc.2010.10.042

34. Bello NA, Cheng S, Claggett B, Shah AM, Ndumele CE, Roca GQ, et al. Association of weight and body composition on cardiac structure and function in the ARIC study (Atherosclerosis Risk in Communities). Circ Heart Fail 2016;9:e002978. https://doi.org/10.1161/CIRCHEARTFAILURE.115.002978

35. Obokata M, Reddy YN, Pislaru SV, Melenovsky V, Borlaug BA. Evidence supporting the existence of a distinct obese phenotype of heart failure with preserved ejection fraction. Circulation 2017;136:6-19. https://doi.org/10.1161/ CIRCULATIONAHA.116.026807

36. Pandey A, Patel KV, Vaduganathan M, Sarma S, Haykowsky MJ, Berry JD, et al. Physical activity, fitness, and obesity in heart failure with preserved ejection fraction. JACC Heart Fail 2018;6:975-82. https://doi.org/10.1016/ j.jchf.2018.09.006

37. Kitzman DW, Brubaker P, Morgan T, Haykowsky M, Hundley G, Kraus WE, et al. Effect of caloric restriction or aerobic exercise training on peak oxygen consumption and quality of life in obese older patients with heart failure with preserved ejection fraction: a randomized clinical trial. JAMA 2016;315:36-46. https://doi.org/10.1001/jama.2015.17346

38. Lytvyn Y, Bjornstad P, Udell JA, Lovshin JA, Cherney DZ. Sodium glucose cotransporter-2 inhibition in heart failure: potential mechanisms, clinical applications, and summary of clinical trials. Circulation 2017;136:1643-58. https://doi.org/ 10.1161/CIRCULATIONAHA.117.030012

39. McMurray JJ, Solomon SD, Inzucchi SE, Køber L, Kosiborod MN Martinez FA, et al.; DAPA-HF Trial Committees and Investigators. Dapagliflozin in patients with heart failure and reduced ejection fraction. N Engl J Med 2019 Sep 19;381:1995-2008. https://doi.org/10.1056/NEJMoa1911303

40. Chrysant SG, Chrysant GS. Obesity-related heart failure with preserved ejection fraction: new treatment strategies. Hosp Pract 2019;47:67-72. https://doi.org/10.1080/ 21548331.2019.1575662

41. EMPagliflozin outcomE tRial in Patients With chrOnic heaRt Failure With Preserved Ejection Fraction (EMPERORPreserved). ClinicalTrials.gov Identifier: NCT03057951. https://ClinicalTrials.gov/show/NCT03057951 [cited 2019 Dec 24]

42. ter Maaten JM, Damman K, Verhaar MC, Paulus WJ, Duncker DJ, Cheng C, et al. Connecting heart failure with preserved ejection fraction and renal dysfunction: the role of endothelial dysfunction and inflammation. Eur J Heart Fail 2016;18:588-98. https://doi.org/10.1002/ejhf.497

43. Shah SJ, Kitzman DW, Borlaug BA, van Heerebeek L, Zile MR, Kass DA, et al. Phenotype-specific treatment of heart failure with preserved ejection fraction: a multiorgan roadmap. Circulation 2016:134:73-90. https://doi.org/10.1161/ CIRCULATIONAHA.116.021884

44. Kotecha D, Lam CS, Van Veldhuisen DJ, Van Gelder IC, Voors AA, Rienstra M. Heart failure with preserved ejection fraction and atrial fibrillation: vicious twins. J Am Coll Cardio 2016;68:2217-28. https://doi.org/10.1016/j.jacc.2016.08.048

45. Santhanakrishnan R, Wang N, Larson MG, Magnani JW McManus DD, Lubitz SA, et al. Atrial fibrillation begets heart failure and vice versa: temporal associations and differences in preserved versus reduced ejection fraction. Circulation 2016:133:484-92. https://doi.org/10.1161/ CIRCULATIONAHA.115.018614 
46. Kaye DM, Silvestry FE, Gustafsson F, Cleland JG, van Veldhuisen DJ, Ponikowski P, et al. Impact of atrial fibrillation on rest and exercise haemodynamics in heart failure with mid-range and preserved ejection fraction. Eur J Heart Fail 2017;19:1690-7. https://doi.org/10.1002/ejhf.930

47. Black-Maier E, Ren X, Steinberg BA, Green CL, Barnett AS, Rosa NS, et al. Catheter ablation of atrial fibrillation in patients with heart failure and preserved ejection fraction. Heart Rhythm 2018;15:651-7. https://doi.org/10.1016/j.hrthm.2017.12.001

48. RCT STALL-HFpEF. Randomised controlled study of atrial fibrillation and left ventricular remodelling in heart failure with preserved ejection fraction. Impact on pulmonary capillary wedge pressure. Australian New Zealand Clinical Trials Registry Registration number: ACTRN12618000292279. http://www.anzctr.org.au/ ACTRN12618000292279.aspx [cited 2019 Dec 24]

49. Böhm M, Perez AC, Jhund PS, Reil JC, Komajda M, Zile MR, et al.; I-Preserve Committees and Investigators. Relationship between heart rate and mortality and morbidity in the irbesartan patients with heart failure and preserved systolic function trial (I-Preserve). Eur J Heart Fail 2014;16:778-87. https://doi.org/10.1002/ejhf.85

50. Komajda M, Isnard R, Cohen-Solal A, Metra M, Pieske B, Ponikowski $\mathrm{P}$, et al:; prEserveD left ventricular ejectlon fraction chronic heart Failure with ivabradine studY (EDIFY) Investigators. Effect of ivabradine in patients with heart failure with preserved ejection fraction: the EDIFY randomized placebo-controlled trial. Eur J Heart Fail 2017;19:1495-503. https://doi.org/10.1002/ejhf.876

51. Cleland JG, Bunting KV, Flather MD, Altman DG, Holmes J, Coats AJ, et al.; Beta-blockers in Heart Failure Collaborative Group. Beta-blockers for heart failure with reduced, midrange, and preserved ejection fraction: an individual patientlevel analysis of double-blind randomized trials. Eur Heart J 2018;39:26-35. https://doi.org/10.1093/eurheartj/ehx564

52. Pal N, Sivaswamy N, Mahmod M, Yavari A, Rudd A, Singh S, et al. Effect of selective heart rate slowing in heart failure with preserved ejection fraction. Circulation 2015:132:1719-25. https://doi.org/10.1161/CIRCULATIONAHA.115.017119

53. Borlaug BA, Melenovsky V, Russell SD, Kessler K, Pacak K, Becker LC, et al. Impaired chronotropic and vasodilator reserves limit exercise capacity in patients with heart failure and a preserved ejection fraction. Circulation 2006;114:2138-47. https://doi.org/10.1161/CIRCULATIONAHA.106.632745

54. Efficacy study of pacemakers to treat slow heart rate in patients with heart failure (RAPID-HF) ClinicalTrials.gov Identifier: NCT02145351. https://ClinicalTrials.gov/show/ NCT02145351 [cited 2019 Dec 24]

55. Hwang SJ, Melenovsky V, Borlaug BA. Implications of coronary artery disease in heart failure with preserved ejection fraction. J Am Coll Cardiol 2014;63 25 Pt A:2817-27. https://doi.org/10.1016/j.jacc.2014.03.034

56. Hoeper MM, Lam CS, Vachiery JL, Bauersachs J, Gerges C Lang IM, et al. Pulmonary hypertension in heart failure with preserved ejection fraction: a plea for proper phenotyping and further research. Eur Heart J 2017;38:2869-73. https://doi.org/10.1093/eurheartj/ehw597

57. Guazzi M. Pulmonary hypertension in heart failure preserved ejection fraction: prevalence, pathophysiology, and clinical perspectives. Circ Heart Fail 2014;7:367-77. https://doi.org/ 10.1161/CIRCHEARTFAILURE.113.000823

58. Kaye DM, Nanayakkara S, Vizi D, Byrne M, Mariani JA. Effects of milrinone on rest and exercise hemodynamics in heart failure with preserved ejection fraction. J Am Coll Cardiol 2016:67:2554-6. https://doi.org/10.1016/j.jacc.2016.03.539

59. Scott PA, Kingsley GH, Scott DL. Non-steroidal anti-inflammatory drugs and cardiac failure: meta-analyses of observational studies and randomised controlled trials. Eur J Heart Fail 2008:10:1102-7. https://doi.org/10.1016/j.ejheart.2008.07.013

60. Hernandez AV, Usmani A, Rajamanickam A, Moheet A. Thiazolidinediones and risk of heart failure in patients with or at high risk of type 2 diabetes mellitus: a meta-analysis and meta-regression analysis of placebo-controlled randomized clinical trials. Am J Cardiovasc Drugs 2011;11:115-28. https://doi.org/10.2165/11587580-000000000-00000
61. Patel K, Fonarow GC, Ahmed M, Morgan C, Kilgore M, Love TE, et al. Calcium channel blockers and outcomes in older patients with heart failure and preserved ejection fraction. Circ Heart Fail 2014;7:945-52. https://doi.org/ 10.1161/CIRCHEARTFAILURE.114.001301

62. Kostis JB, Packer M, Black HR, Schmieder R, Henry D, Levy E. Omapatrilat and enalapril in patients with hypertension: the Omapatrilat Cardiovascular Treatment vs. Enalapril (OCTAVE) trial. Am J Hypertens 2004;17:103-11. https://doi.org/10.1016/j.amjhyper.2003.09.014

63. Redfield MM, Chen HH, Borlaug BA, Semigran MJ, Lee KL, Lewis G, et al.; RELAX Trial. Effect of phosphodiesterase-5 inhibition on exercise capacity and clinical status in heart failure with preserved ejection fraction: a randomized clinical trial. JAMA 2013;309:1268-77. https://doi.org/10.1001/ jama.2013.2024

64. Søndergaard L, Reddy V, Kaye D, Malek F, Walton A Mates $M$, et al. Transcatheter treatment of heart failure with preserved or mildly reduced ejection fraction using a novel interatrial implant to lower left atrial pressure. Eur J Heart Fail 2014;16:796-801. https://doi.org/10.1002/ejhf.111

65. Hasenfuß G, Hayward C, Burkhoff D, Silvestry FE, McKenzie S, Gustafsson F, et al.; REDUCE LAP-HF study investigators. A transcatheter intracardiac shunt device for heart failure with preserved ejection fraction (REDUCE LAP-HF): a multicentre, open-label, single-arm, phase 1 trial. Lancet 2016;387:1298-304. https://doi.org/10.1016/ S0140-6736(16)00704-2

66. Feldman T, Mauri L, Kahwash R, Litwin S, Ricciardi MJ, van der Harst P, et al.; REDUCE LAP-HF I Investigators and Study Coordinators. Transcatheter interatrial shunt device for the treatment of heart failure with preserved ejection fraction (REDUCE LAP-HF I [Reduce Elevated Left Atrial Pressure in Patients With Heart Failure]): a phase 2, randomized, sham-controlled trial. Circulation 2018:137:364-75. https://doi.org/10.1161/CIRCULATIONAHA.117.032094

67. Kaye DM, Hasenfuß G, Neuzil P, Post MC, Doughty R, Trochu JN, et al. One-year outcomes after transcatheter insertion of an interatrial shunt device for the management of heart failure with preserved ejection fraction. Circ Heart Fail 2016:9:e003662. https://doi.org/10.1161/ CIRCHEARTFAILURE.116.003662

68. Shah SJ, Feldman T, Ricciardi MJ, Kahwash R, Lilly S, Litwin S, et al. One-year safety and clinical outcomes of a transcatheter interatrial shunt device for the treatment of heart failure with preserved ejection fraction in the reduce elevated left atrial pressure in patients with heart failure (REDUCE LAP-HF I) trial: a randomized clinical trial. JAMA Cardiol 2018;3:968-77. https://doi.org/10.1001/ jamacardio.2018.2936

69. REDUCE LAP-HF TRIAL II ClinicalTrials.gov Identifier: NCT03088033. https://ClinicalTrials.gov/show/ NCT03088033 [cited 2019 Dec 24]

70. Adamson PB, Abraham WT, Bourge RC, Costanzo MR, Hasan A, Yadav C, et al. Wireless pulmonary artery pressure monitoring guides management to reduce decompensation in heart failure with preserved ejection fraction. Circ Heart Fail 2014;7:935-44. https://doi.org/10.1161/ CIRCHEARTFAILURE.113.001229

71. Abraham WT, Stevenson LW, Bourge RC, Lindenfeld JA, Bauman JG, Adamson PB; CHAMPION Trial Study Group Sustained efficacy of pulmonary artery pressure to guide adjustment of chronic heart failure therapy: complete followup results from the CHAMPION randomised trial. Lancet 2016;387:453-61. https://doi.org/10.1016/S0140-6736(15)00723-0

72. Shah SJ, Cogswell R, Ryan JJ, Sharma K. How to develop and implement a specialized heart failure with preserved ejection fraction clinical program. Curr Cardiol Rep 2016;18:122. https://doi.org/10.1007/s11886-016-0802-1 